\title{
Explanatory Models of Inmate HIV Risk Behaviors: Does a Fatalistic Model Exist?
}

\author{
Joseph A. Balogun ${ }^{*}$, Titilayo C. Abiona ${ }^{2,3}$, Ivonne K. Anguh ${ }^{3}$ \\ ${ }^{1}$ Department of Health Studies, Chicago State University, Chicago, USA \\ ${ }^{2}$ Oak Forest Health Center of Cook County, Oak Forest, USA \\ ${ }^{3}$ HIV/AIDS Research and Policy Institute, Chicago State University, Chicago, USA \\ Email: ${ }^{\text {jjbalogun@csu.edu }}$
}

Received 24 February 2015; accepted 20 May 2015; published 26 May 2015

Copyright (C) 2015 by authors and Scientific Research Publishing Inc.

This work is licensed under the Creative Commons Attribution International License (CC BY). http://creativecommons.org/licenses/by/4.0/

(c) () Open Access

\section{Abstract}

The deprivation, importation, situational, and administrative control models have been used to explain inmate violence. More recently, HIV risk behaviors of inmates have been explained with the deprivation and importation models. The goal of this study is to assess the utility of these models in describing inmate HIV risk behaviors and to identify additional models that may exist. Forty seven ex-offenders released from prison within three months of the study were recruited from a community based organization. They participated in focus group discussions that explored the contexts surrounding inmate engagement in HIV risk behaviors in prison. Data were analyzed using NVivo 7 and results were organized into themes. Inmates engaged in sex in exchange for money and for affection. Inmates who were drug users before incarceration were more likely to abuse drugs in prison. Security measures, if effective, deterred the entrance of illegal substance into prison, but when security is lax, inmates take the opportunity to engage in sex, and illegal substances are brought into prison. Our results reveal that deprivation, importation, situational, and administrative control factors are associated with HIV risk behaviors among inmates and they can be used in explaining these behaviors. The association of risk behaviors with long or life sentences suggests that fatalism may play a role in risk behaviors among inmates. Fatalism is a factor which requires future examination.

\section{Keywords}

HIV, Risk Behaviors, Explanatory Models, Inmates

\footnotetext{
${ }^{*}$ Corresponding author.
} 


\section{Introduction}

Explanatory paradigms such as the deprivation, importation, situational, and administrative control models have been tested for their effectiveness in explaining inmate behaviors. Researchers have utilized these models mainly in relation to understanding the determinants of prison violence [1] [2]. In recent years, however, the explanatory utility of some previously described models, mainly the deprivation and importation models, have been applied to findings from studies of HIV risk behaviors of inmates [3] [4].

The deprivation model posits that inmate behavior is a function of the prison environment. The prison environment deprives inmates of certain needs causing "pains of imprisonment" [5] [6]. These pains include deprivation of liberty, goods and services, heterosexual relationships, autonomy, and security. It is believed that the absence of these needs being fulfilled in the usual way leads to behavioral changes in the inmate, known as modes of response. The loss of the usual way of fulfilling certain needs results in an array of behavioral responses, most of which involve adherence to the "inmate code". The adherence to the inmate code helps the inmates to neutralize the pains of imprisonment so that they become "prisonized", enabling them to survive and cope with incarceration.

The importation model assumes that behaviors in prison are based on pre-prison characteristics, culture, environment, behaviors and experiences of inmates [7]. The model posits that criminals develop certain attitudes in society and these tendencies remain intact when the criminal is incarcerated and those same attitudes guide their behavioral responses in prison [8]. The deprivation and importation models complement each other and explain how the pre-prison characteristics, experiences and behaviors of inmates coalesce with the in-prison characteristics, experiences and behaviors of inmates to create a subculture that promotes high-risk HIV transmission behaviors.

The situational model assumes that the sources for the initiation and direction of behavior are the result of primarily situational factors [9]. Such factors are the season of the year, the time of day, the location, security, and a complex interplay between inmates, prison officials, and the settings in which the interactions occur [10]. Our objective of determining "where, when, and with whom do risk behaviors occur" is based on the situational model [11]. The situational model has been used to examine other inmate behaviors such as violence [2].

Administrative control theorists suggest that administration should be included as a determinant of inmate behaviors. Administrative control theory is based on the assumption that control is necessary in corrections management [12]-[14]. Two specific types of control have been suggested: coercive and remunerative controls. Coercive control rests on the threat or application of physical sanctions, generation of frustration through control, or the restriction on achievement of personal needs through force. On the other hand, remunerative controls function as incentives and rest on the provision of material resources and rewards [2]. Studies have shown that in correctional facilities where there is a balance of coercive and remunerative controls, there is less incidence of misconduct in comparison to institutions that used only coercion as the means of control [15]-[17].

The objectives of this study were to gain an in-depth understanding of the contexts of HIV risk behaviors that occur in the prison environment, and to assess the possibility of other models in addition to the deprivation, importation, situational, and administrative policy models that were used in explaining the HIV risk behaviors of inmates. Studying inmate risk behaviors in the context of these models could provide a framework that would be useful in developing HIV preventions interventions for inmates.

\section{Methods}

\subsection{Study Setting and Participants}

The study was conducted at a Community Based Organization [CBO] in Chicago which provides comprehensive HIV/AIDS prevention services to ex-offenders. Eight FGDs were conducted with four groups of men and women respectively. The sampling methodology for the study was purposive. While we desired to have between six and eight participants in each focus group, this was not possible with the women. Each female FGD consisted of five participants. The socio-demographic characteristics of the study participants have been described elsewhere [18]. In brief, forty-seven recently released ex-offenders [27 women and 20 men] participated in the FGDs. Over half of the study participants [53\%] were less than 40 years old and 57\% of them had never been married. Eighty-five percent were African-Americans, at least 55\% of them completed high school and $81 \%$ 
identified as heterosexual.

Study participants were recruited from the CBO from weekly new arrivals. Inclusion criteria for eligibility to participate in the study include age of at least 18 years old; incarceration for at least six months in an Illinois prison [not jail] during the last incarceration; release from prison for less than three months; and ability to be able read, write and understand English. A minimum age of 18 years was chosen because this is the legal age of adulthood. We decided on a minimum incarceration period of six months because we felt a shorter time frame may not be adequate for becoming prisonized and engaging in risk behaviors. We limited the time post release to less than 3 months to avoid recall bias. The study was approved by the Institutional Review Board at Chicago State University.

\subsection{Data Collection Procedures}

On the data collection days, potential participants received initial brief information about the study and its requirements, and they were screened for eligibility. Once a group of six [five for women] willing and eligible participants had been convened, they were moved to a separate room where the FGD took place. A member of the research team read a recruitment script to the participants that provided detailed information about the study, its goals, potential benefits and risks. Permission to record the discussion on audio tape was sought. Participants had their questions about the study answered by study personnel. All participants provided written informed consent.

The FGDs were moderated by two trained facilitators and each FGD session had a note taker. Data were collected using an FGD guide developed specifically for the study based on the findings of our cross-sectional prison survey of HIV risk behaviors [19]. The discussion guide was pre-tested with one group of men and women. The questions were based on exploring the perceptions and knowledge of recently released ex-offenders regarding the occurrence of risk behaviors [alcohol use, substance use, tattooing, and body piercing] in prison identified in the survey, obtain broader perspectives about the contexts [when, who, where and how] of the risk behaviors and learn about factors which facilitate or hinder the behaviors. Each FGD lasted between 60 and 90 minutes. Participants received \$25 each for their time and travel expense, they also received HIV prevention educational pamphlets, and condoms.

\subsection{Data Management and Analysis}

The confidentiality of the data was protected by the investigators and the project staff. All raw data were anonymous and were kept in the possession of the research staff at all times.

Survey data were coded and analyzed using the Statistical Package for the Social Sciences [SPSS] software, version 16 for Windows. Results were summarized with descriptive statistics. Tape records of focus group discussions were downloaded onto a computer and transcribed verbatim [20]. Field notes were word processed. FGD data were analyzed using the NVivo 7 software for qualitative data analysis. Data were coded based on the pre-determined themes in the discussion guide, and emerging themes were added. Results are presented to highlight the thematic areas in the guide. A combination of paraphrase and direct quotes were used to convey a participant's main points and to adequately represent his or her own words.

\section{Results}

\subsection{Utility of Models to Explain HIV Risk Behaviors in Prison}

The risk behaviors examined include illegal drugs and alcohol, needle sharing for intravenous drug use, tattooing and body piercing, and sexual intercourse. Alcohol and illegal drugs are associated with risky sexual behavior such as unprotected sex and multiple partners. Intravenous drug use, tattooing and body piercing have the issue of needle sharing in common.

\subsection{Alcohol}

Study participants responses regarding alcohol use among prison can be explained by the deprivation, importation, administrative control models. Fatalism also seems to be a factor associated with alcohol use. Alcohol is prohibited in prison. For inmates who consumed alcohol regularly and who may be dependent on alcohol before incarceration, they are deprived. This deprivation makes them become creative in producing alcohol, which is 
commonly called "hooch" or "white lightning”. Most of the alcohol is made from fruits and other food items.

It's made from fruits that we get from the kitchen. Well, you just put the fruit in there and let it sit for so long. [Female Participant].

Wine, there's several ways you can make it. I mean, yeah, wine, several ways you can make it. You can get some ketchup, you can get some tomato paste, get you some rice and potatoes. Anything you get, you gotta have enough sugar. You can get some grape juice, some orange juice, get you some rice, let it sit, and you got alcohol. [Male Participant].

It was a recurring theme in all the FGD groups that alcohol intake used to be very common in the prisons. Alcohol use is associated with risky sexual behavior hence it is included in the study of HIV risk behaviors.

In the last couple of years, alcohol intake has become less common because of stricter repercussions [administrative control] if an inmate is caught drinking or in possession of alcohol. The quote below by a male participant is typical.

Well, like I said, I've been locked up the last ten years, and where I been, that stuff [drinking alcohol] isn't going on. You know, $\cdots$, it's really not going on these days. And like give or take, about the last eight years it's really -it's too dangerous, there's too many bad results for the inmates, and they wising up, you know. They're not taking those risks anymore. Most inmates now just trying to do their time and get outta there. [Male Participant].

Occasionally, a correctional officer may provide inmates alcohol, also an issue of administrative control. Hence, administrative control can either deter or encourage risk behaviors among inmates.

But if you meet the right officer and you know, and y'all get a-y'all form a bond, guess what? You ain't never gotta make hooch no more. [Male Participant].

In response to questions about which inmates were more likely to drink alcohol in prison, some participants believed that all inmates could drink alcohol, but others said alcohol abuse was more common among inmates who had mental illness, those who had some kind of addictions before incarceration and "old timers" [persons who have long sentences]. These findings provide support for importation and fatalism as explanatory factors.

Anyone could drink $\cdots$ but typically, it be people who been there a long time, those with many years. [Male Participant].

\subsection{Marijuana}

Participants reported that inmates use marijuana. The deprivation, importation, administrative control, and fatalistic models are applicable to marijuana use in prison. That marijuana gets into prison through visitors and correctional officers is a factor related to administrative control.

Sometimes guards bring it [marijuana] in and sometimes your visitors. [Female Participant].

Somebody brings it [marijuana]. An officer brings it [marijuana] in. [Male Participant].

Similar to alcohol, marijuana use has decreased in prison because inmates have less access to it as a result of better security and stiffer penalties.

They don't cut down a lot [marijuana]. It's kind of hard, you know. Because when I was in there, quite a few people got busted bringing stuff in. [Female participant].

When asked who was more likely to smoke marijuana in prison, study participants reported it could be anyone because it makes inmates feel better. Some participants revealed that marijuana use was more common among persons on long or life sentences and those who were addicted to marijuana before incarceration, and gang members. These findings can be explained by deprivation, importation, and fatalism.

Anybody wants to do it [smoke marijuana], cause they in there; anything to make you feel better. [Another participant] It help you escape. [Male Participant].

Most likely, like they say, anyone. But the most likely people that smoke marijuana's about-is the people that's hooked up. You know, you've gotta be plugged, you've gotta be in some type of organization. You know what I'm talking about? Some type of gang. See, you ain't gonna see too many neutrons, people that's-we call them neutrons that's not hooked up—smoking marijuana and drinking $\cdots$ [Male Participant].

... they got to flip 35 calendars over, you know, whatever they can get their hands on, some already they don't care. [Female Participant]. 


\subsection{Other Illegal Drugs and Needles}

The use of illegal drugs leads to impaired judgment and increases the likelihood of unprotected sexual intercourse and multiple sexual partners. Needle sharing is directly related to the acquisition of blood borne infections especially in prison where cleaning agents are not readily available.

Study participants reported that inmates used other illegal drugs that were available on the street such as cocaine, crack cocaine, heroin, and Phencyclidine [PCP]. These drugs usually got into prison through visitors or guards. Importation and administrative control models can explain these findings.

I just - I believe that nine out of ten-if you was to get ten people together that's been incarcerated, nine of them gonna be in jail for something drug-related. [Male Participant].

That it has become more difficult to get illegal drugs into prison because of tighter surveillance [administrative control] was a recurring theme in all the groups.

You know, $\cdots$ they done shut down a lotta stuff, you know, by tightening up $\cdots$. It's still there, you know, it ain't like it ain't there $\cdots$. They know it is. It's, you know, like, I got a saying-"Anything manmade can be bought." [Male Participant].

You know, but like now, its more-like I say, it's—in the tightening up, it's kind of hard to get a hold of syringes $\cdots$ they cracked down. [Male Participant].

But occasionally, some lapses in surveillance [situational factor] give inmates access to syringes and needles.

… you got hospital workers that's inmates, ... so they got access to [INAUDIBLE], you know, and like you a doctor, you might accidentally leave that drawer open, I know there's some syringes in there, I grab a few of 'em, go on about my business. [Male Participant].

Some participants reported that some inmates share injecting needles because needles are contraband so they are scarce [deprivation of goods].

It's common to share. [another participant]'Cause it's hard to get. [Male Participant].

When asked about inmates who would typically use illegal drugs, participants stated it could be anyone, but noted it was more likely to be persons who were users before incarceration, thus supporting the importation model.

They all have drugs. [Female Participant].

All-everyone there $\cdots$ [Another participant]. More than not $\cdots$ that did it [used drugs]on the street. [Male Participants].

Yeah, they $\cdots$ they adapted to [drugs]. That's their lifestyle. [Female Participant].

You don't get it, you get sick. [Female Participant].

I think that all-most cases now are drug-related. You know what I'm saying? You got more drug-related cases that's in the system than anything else now. So it was already drug-related; once you get done, you gonna go back to what you feel at home with, no matter where you at, cause that what you used to doing. [Male Participant].

You feel comfortable when you can use drugs, it eases your mind. [Male Participant].

Most of us entire prison with an addiction problem, and you know, it take you know, some [INAUDIBLE] stuff to get over that type of stuff. [Male Participant].

\subsection{Sexual Intercourse}

All participants mentioned that oral, vaginal and anal sex occurs in prison. Both same sex and heterosexual relationships are said to occur among inmates and between inmates and prison staff. Although some inmates experience homosexual relationships for the first time during incarceration, same or bisexual orientation often exist before incarceration. This finding provides support for the importation model.

Many of them be homosexual before $\cdots$. [incarceration]. [Male Participant].

Participants gave various reasons why sex occurs in prison; they include boredom, curiosity [especially in relation to same sex liaisons], rape, debt repayment, exchange for money, groceries or drugs, loving relationships between inmates, or simply a natural desire for sex. Some of these reasons show deprivation as exemplified by these quotes:

And some of them $\cdots$ and some of them really care $\cdots$ claim they really care about the person. [Female Participant]. 
A lotta guys, you know, been locked up a while. When they get these-they call them their kids, $\cdots$ they treat 'em like they're their own, they move 'em in the room with 'em. The guy cooks, clean, wash-he treats 'em just like you would treat your wife. You know what I'm saying? ') and they have sex with them. [Male Participant].

When asked about the inmate who was more likely to have sex, some participants felt persons with long sentences, including life sentences were more likely to engage in sexual activity, suggesting fatalistic attitudes associated with incarceration.

And if you got time, you know you doing a long time $\cdots$ You might as well just get a girlfriend. [another participant] And the time go faster. [Female Participants].

And the long timers, you know, this is what I'm gonna do [have sex] just because I'm here. [Female Participant].

Regarding protection during sex, the general response was that condoms are not available in prison, and inmates rarely use protection. However, male participants mentioned that rubber gloves and saran wraps are sometimes improvised for condoms. Deprivation of goods leads to creativity among inmates.

...They use rubber gloves and-what else they use? Some Saran wrap, the plastic kind of stuff. [Male Participant].

\subsection{Tattooing}

Importation seems to play a part in inmates getting tattoos in prison.

No, not really, cause it's a trend now. You know, tattoos is a trend; you got more, you got, you know, like you used to have gun shops and liquor stores around the corner, you got tattoo shops all over the neighborhoods now. So it's like a trend with tattooing. Well, I'd say it's about equal, you know. [Male Participant].

Some participants believed that it has become more difficult to get tattoos in prison because it is an illegal practice which carries penalties [administrative control], as exemplified by this quote from a male participant:

-.And also, from my experience, there's more of a crackdown. It's harder to get the necessary stuff to make them jailhouse tattoos nowadays. And it ain't the fashion like it was. When I first went, a long time ago, it was a fad in the prison system - everybody wanted to get tattoos, wanted to link up with something. But today, it-like you said, there's body art on the street, and it's-[phew] they can't even touch it in the penitentiary no more.

Participants mentioned varying reasons why inmates get tattoos in prison. Tattoos serve as symbols of remembrance, it is part of prison culture to get tattoos, it is a way of passing time, or an avenue of making a statement about one's personality. Inmates also get tattoos simply because they like tattoos. Some of these reasons suggest deprivation.

...when you are inside, the only thing is just remember the good things, the bad things, and you put something on you [tattoos] just to remember that thing $\cdots$ [Female Participant].

-..or they maybe have mother's or father's picture, their relatives in life put on 'em for remembering. [Male Participant].

Situational factors were largely responsible for the venues where tattooing occurs. Both men and women opined that tattooing was usually done in the cells, [referred to at times as dorms, behind closed doors, lock up etc.] or anywhere else when an opportunity arises, such as when the guards are not watching.

Yeah. [getting a tattoo] And it's basically when you're in-when you're either locked up or there's no guards around. [Female Participant].

Well, from my experience in the maximum security, there wasn't no time. Whenever we was out on the yard, in the cell, - wherever there was convenient, you got a tattoo. [Male Participant].

\section{Discussion}

Our findings in this study reveal that inmates engage in risk behaviors that could predispose them to acquiring HIV infection and other blood borne viruses, notably Hepatitis B and C. Eliminating the occurrence of risk behaviors among inmates is the ideal goal for the prevention of HIV transmission in prison. However, this is inherently difficult, if not impossible. Therefore steps need to be taken to reduce risk behaviors and protect inmates and the public from HIV and other blood borne infections.

An understanding of relevant models that can explain HIV risk behaviors of inmates can provide theoretical bases for HIV prevention programs. The findings in this study provide support for the deprivation, importation, 
situational and administrative control models of inmate behaviors and we suggest that a fatalistic model may also exist (Figure 1).

The deprivation model proposes that inmates get involved in certain behaviors because they are deprived of certain needs such as freedom, resources, relationships and safety, thus they acquire a code of behavior dictated by the prison system. The finding that inmates engaged in sex for money, protection, and affection suggests deprivation. Boredom as a reason for engaging in sex, drug use and getting tattoos also suggests deprivation.

Our participants revealed that although some inmates began using substances in prison, the majority of the inmates who abused substances in prison were users before incarceration. Indeed, studies have shown that many prisoners are incarcerated with established drug use habits [21]-[23]. In one USA study, over two-thirds of newly admitted inmates tested positive for an illegal drug during urine screening [16]. According to the Substance Abuse and Mental Health Administration [SAMHSA], between 50\% - 66\% of offenders meet the DSM-IV criteria for substance dependence [24], much higher than the rate of about $9 \%$ in the general U.S. population [25]. This finding provides support for the importation model which posits that inmates import their pre-incarceration behaviors in the community into prison. The finding also underscores the need for drug dependence treatment in prison. Similarly, although inmates got involved in same sex relationships out of curiosity, rape, or in exchange for goods, some inmates who engaged in homosexual sex were gay or lesbian before incarceration. Furthermore, one reason why inmates got tattoos was because tattooing is a very common activity outside prison. The above observations provide evidence in support of the importation model of inmate behavior.

The results of this study which reveal that inmates engaged in risk behaviors when they had the chance to do so, such as when the guards were not present, or when lenient guards were on duty provide support for the situational model. The situational model assumes that the sources for the initiation and direction of behavior are the result of primarily situational factors [26],such as the season of the year, the time of day, the location, security, and a complex interplay between inmates, prison officials, and the settings in which the interactions occur [27].

In this study, participants reported that the decline in the entry of illegal drugs and other substances into prison, and reduction in tattooing and body piercing are attributable to tighter security measures by correctional staff, and punishment for erring inmates. This finding supports the coercive control portion of the administrative control model. Administrative control could be of two types: coercive and remunerative controls. Coercive control rests on the threat or application of physical sanctions, generation of frustration through control, or the

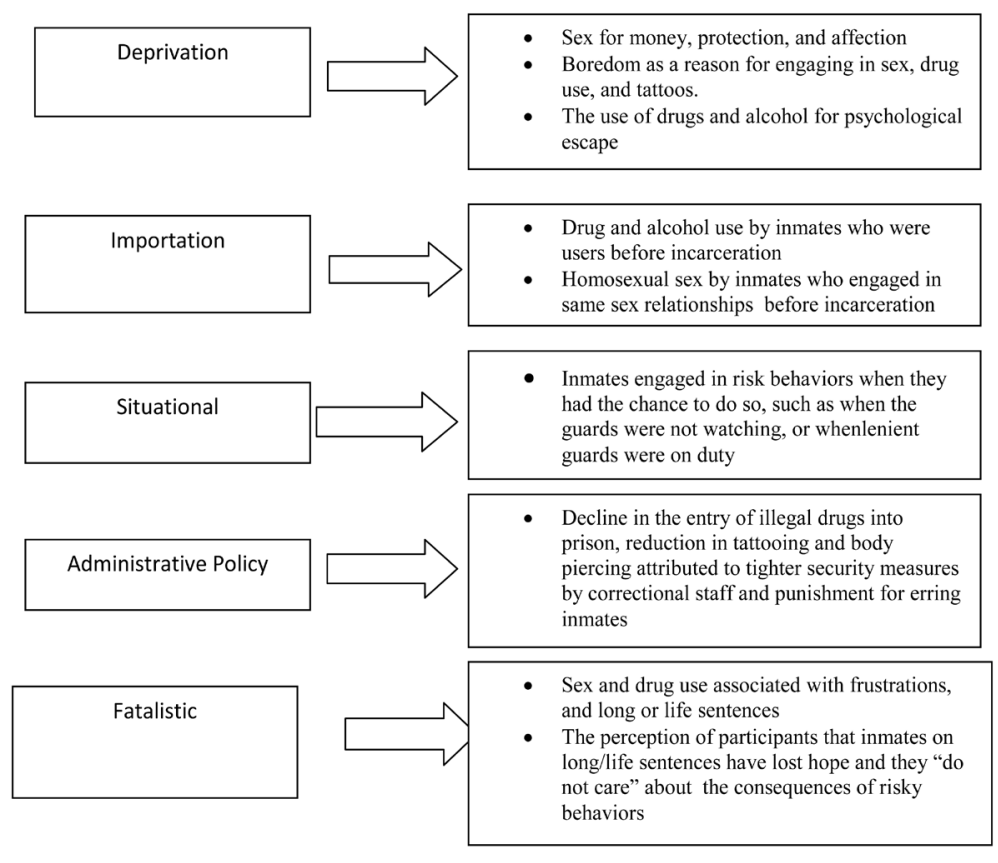

Figure 1. Models of inmate behavior and study findings of HIV Risk Behaviors. 
restriction on achievement of personal needs through force. On the other hand, remunerative controls function as incentives and rest on the provision of material resources and rewards [28]. None of what we learned from our study participants provided support for the remunerative control aspect of the administrative control model.

Our study participants mentioned other reasons why inmates engage in risk behaviors especially sex and drug abuse. These reasons include frustrations associated with being incarcerated, family problems, and fatalistic attitudes because of long or life sentences. Although any inmate could engage in risk behaviors, inmates who had been incarcerated for long periods and those who were on life sentences were more likely to engage in sex and substance abuse [29] [30]. With regards to drug use, it has been "argued that confinement is a predictor of drug use" [12] and several studies have concluded that boredom, hopelessness, and frustration contribute in part to drug use [13] [20]. These observations suggest a fatalistic model of inmate behavior. Further studies of possible fatalism are required. Such studies should assess the relationship between length of incarceration, type of sentence and occurrence of risky behaviors.

\section{Limitations}

This study has some limitations. There is the potential for recall bias. We do not think recall bias would have played a significant role in our findings because study participants were released from prison within three months before data collection. The observations reported are limited to the experiences of the study participants in the prisons where they had served their sentences. Our findings may not represent the situation in all Illinois prisons; consequently caution should be exercised in generalizing our findings to all Illinois prisons and other prisons nationwide.

Although our findings suggest that fatalism may play a role in the HIV risk behaviors of inmates, especially in terms of the characteristics of the inmate who engages in risk behaviors. Our present study must be interpreted with caution because we did not design the qualitative study to test the effectiveness of models used in explaining the HIV risk behaviors of inmates.

\section{Study Significance and Conclusion}

Our findings revealed that HIV risk behaviors of inmates can be explained by previously described models such as the deprivation, importation, situational, and administrative control models. Fatalism may be an additional explanatory factor that needs to be explored further. Providing specific HIV prevention services such as education and risk reduction materials may not be sufficient to reduce HIV transmission among inmates. The explanatory models and the study findings that provide support for them need to be considered and attended to, if HIV transmission in prison is to be halted. For instance, activities to reduce boredom, and psychological counseling to help inmates cope with their frustrations should be provided. Similarly, a system for the early identification of inmates who had abused alcohol and substances prior to incarceration should be developed and such inmates should receive appropriate drug dependence treatment. Tighter security measures should be put in place to prevent illegal substances from getting into prison.

\section{Acknowledgements}

The study authors thank the Illinois General Assembly and the Illinois Department of Public Health for providing funding for this study. We would also like to thank Josie McDonald and Jerry Goldstein for their contribution to data collection.

\section{Conflict of Interest}

The authors have no conflict of interests.

\section{Disclaimer}

The information or content and conclusions are those of the authors and should not be construed as the official position or policy of, nor should any endorsement be inferred by the Illinois General Assembly and the Illinois Department of Public Health. 


\section{References}

[1] Huebner, B.M. (2003) Administrative Determinants of Inmate Violence: A Multilevel Analysis. Journal of Criminal Justice, 31, 107-117. http://dx.doi.org/10.1016/S0047-2352(02)00218-0

[2] Steinke, P. (1991) Using Situational Factors to Predict Types of Prison Violence. Journal of Offender Rehabilitation, 17, 119-132. http://dx.doi.org/10.1300/J076v17n01_09

[3] Jiang, S. and Fisher-Giorlando, M. (2002) Inmate Misconduct: A Test Deprivation, Importation, and Situational Models. The Prison Journal, 82, 335. http://dx.doi.org/10.1177/003288550208200303

[4] Macdonald, J.M. (1999) Violence and Drug Use in Juvenile Institutions. Journal of Criminal Justice, 27, 33-44. http://dx.doi.org/10.1016/S0047-2352(98)00033-6

[5] Hochstetler, A. and De Lisi, M. (2005) Importation, Deprivation, and Varieties of Serving Time: An Integrated-Lifestyle-Exposure Model of Prison Offending. Journal of Criminal Justice, 33, 257-266. http://dx.doi.org/10.1016/j.jcrimjus.2005.02.005

[6] McCorkle, R.C., Miethe, T.D. and Drass, K.A. (1995) The Roots of Prison Violence: A Test of the Deprivation, Management, and “Not-So-Total” Institution Models. Crime \& Delinquency, 41, 317-331. http://dx.doi.org/10.1177/0011128795041003003

[7] Krebs, C.P. and Simmons, M. (2002) Intraprison HIV Transmission: An Assessment of Whether It Occurs, How It Occurs, and Who Is at Risk. AIDS Education and Prevention: Official Publication of the International Society for AIDS Education, 14, 53-64. http://dx.doi.org/10.1521/aeap.14.7.53.23865

[8] Seal, D.W., Belcher, L., Morrow, K., Eldridge, G., Binson, D. and Kacanek, D. (2004) A Qualitative Study of Substance Use and Sexual Behavior among 18- to 29-Year-Old Men While Incarcerated in the United States. Health Education \& Behavior: The Official Publication of the Society for Public Health Education, 31, 775-789. http://dx.doi.org/10.1177/1090198104264134

[9] Sykes, G. (1958) The Society of Captives: A Study of Maximum Security Prisons. Princeton University Press, Princeton.

[10] Sykes, G.M. and Messinger, S.L. (1960) The Inmate Social System. In: Cloward, R., Ed., Theoretical Studies in Social Organization of the Prison, Social Science Research Council, 5-19.

[11] Irwin, J. and Cressey, D.R. (1962) Thieves, Convict, and the Inmate Culture. Social Problems, 10, 142-155. http://dx.doi.org/10.2307/799047

[12] Endler, N.S. and Magnusson, D. (1976) Towards an Interactional Psychology of Personality. Psychological Bulletin, 83, 956-974. http://dx.doi.org/10.1037/0033-2909.83.5.956

[13] Flanagan, T.J. (1983) Correlates Institutional Misconduct among State Prisoners. Criminology, 21, 29-40. http://dx.doi.org/10.1111/j.1745-9125.1983.tb00249.x

[14] Irwin, J. (1980) Prisons in Turmoil. Little Brown and Company, Boston.

[15] Dilulio Jr., J.J. (1987) Governing Prisons: A Comparative Study of Correctional Management. Free Press, New York.

[16] Reisig, M.D. (1998) Rates of Disorder in Higher-Custody State Prisons: A Comparative Analysis of Managerial Practices. Crime \& Delinquency, 44, 229-244. http://dx.doi.org/10.1177/0011128798044002003

[17] Useem, B. and Kimball, P. (1991) States of Siege: US Prison Riots, 1971-1986. Oxford University Press, New York, 227-231.

[18] Abiona, T.C., Balogun, J.A., Adefuye, A.S. and Sloan, P.E. (2010) Body Art Practices among Inmates: Implications for Transmission of Blood Borne Infections. American Journal of Infection Control, 38, 121-129. http://dx.doi.org/10.1016/j.ajic.2009.06.006

[19] Abiona, T.C., Adefuye, A.S., Balogun, J.A. and Sloan, P.E. (2009) Gender Differences in HIV Risk Behaviors of Inmates. Journal of Women's Health, 18, 65-71. http://dx.doi.org/10.1089/jwh.2008.0941

[20] Etzioni, A. (1961) A Comparative Analysis of Complex Organizations: On Power, Involvement, and Their Correlates. Free Press of Glencoe, New York.

[21] Colvin, M. (1992) The Penitentiary in Crisis: From Accommodation to Riot in New Mexico. State University of New York Press, Albany.

[22] Maruschak, L.M. and Beaver, R. (2009) HIV in Prisons, 2007-08. Bureau of Justice Statistics (BJS) Bulletin, NCJ 228307, December 2009, US Department of Justice, Washington DC, 12 p. http://bjs.ojp.usdoj.gov/content/pub/pdf/hivp08.pdf

[23] WHO/UNODC/UNAIDS (2007) Evidence for Action Technical Papers. Effectiveness of Interventions to Address HIV in Prisons. http://www.who.int/hiv/topics/idu/prisons/en/index.html

[24] Mumola, C. and Karberg, J. (2006) Drug Use and Dependence, State and Federal Prisoners, 2004. Bureau of Justice 
Statistics Special Report, NCJ 213530, US Department of Justice, Office of Justice Programs, Washington DC, 11 p. http://bjs.ojp.usdoj.gov/content/pub/pdf/dudsfp04.pdf

[25] Substance Abuse and Mental Health Services (SAMSHA) (2011) Results from the 2010 National Survey on Drug Use and Health (NSDUH): Summary of National Findings. NSDUH Series H-41, HHS Publication No. (SMA) 114658, Substance Abuse and Mental Health Services Administration, Rockville, 143 p. http://oas.samhsa.gov/NSDUH/2k10NSDUH/2k10Results.pdf

[26] Wright, K.N. (1994) Effective Prison Leadership. William Neil, Binghamton.

[27] Patton, M. (2002) Qualitative Research and Evaluation Methods. 3rd Edition, Sage Publisher, Thousand Oaks.

[28] Calzavara, L.M., Burchell, A.N., Schlossberg, J., Myers, T., Escobar, M., Wallace, E., et al. (2003) Prior Opiate Injection and Incarceration History Predict Injection Drug Use among Inmates. Addiction, 98, 1257-1265. http://dx.doi.org/10.1046/j.1360-0443.2003.00466.x

[29] Hiller, M.L., Knight, K. and Simpson, D.D. (1999) Prison-Based Substance Abuse Treatment, Residential Aftercare and Recidivism. Addiction, 94, 833-842. http://dx.doi.org/10.1046/j.1360-0443.1999.9468337.x

[30] Hughes, R. and Huby, M. (2000) Life in Prison: Perspectives of Drug Injectors. Deviant Behavior, 21, 451-479. http://dx.doi.org/10.1080/01639620050085843 